\title{
ANALISIS USAHATANI DAN FAKTOR-FAKTOR YANG MEMPENGARUHI PENDAPATAN USAHATANI JERUK GERGA DI DESA RIMBO PENGADANG KECAMATAN RIMBO PENGADANG KABUPATEN LEBONG
}

\author{
(An Analysis Of Farming and its factors toward Gerga Orange farming revenue at \\ Rimbo Pengadang Village, Rimbo Pengadang District, Lebong Regency)
}

\author{
Fery Murtiningrum $^{1 *}$, Eddi Silamat ${ }^{1}$. \\ ${ }^{1}$ Program Studi Agribisnis Sekolah Tinggi Ilmu Pertanian Rejang Lebong (STIPER RL) \\ Jl. Basuki Rahmat No. 13 Dwi Tunggal, Curup Rejang Lebong Bengkulu \\ *Corresponding Author, Email: ferymurtiningrum@yahoo.co.id
}

\begin{abstract}
In Bengkulu Province, especially at Lebong Regency is one of the regions which has various potentials that support the national economy, both agriculture, plantation, fisheries, livestock and forestry potential. In agriculture, it is an area that suitable for developing various types of horticultural crops such as gerga oranges, because it is supported by loose and fertile soil conditions and also supported by altitudes ranging from 800-1000 masl. One of the gerga oranges producing areas in Lebong Regency is Rimbo Pengadang Village, Rimbo Pengadang District. This study aims to determine the revenue of oranges farming in Rimbo Pengadang Village, to determine the effect of land area, age, education, and number of family dependents on oranges farming revenue in Rimbo Pengadang Village and to know the development of gerga culture in Rimbo Pengadang Village in the last 5 years. The data used are primary data and secondary data. The data analysis tool used $P D=T R-T C$, where: $P d=$ Agricultural revenue $(R p / U t) . T R=$ Total revenue $(R p / U t)$ and $T C=$ Total cost $(R p / U t)$. The method used to determine the efficiency of sawn oranges farming used in the formula: $R / C$ Ratio. From the results of the study, it is known that the average revenue of the orange saw farming business is $R p$. $59.759 .158,52$ per year / UT. With an average revenue of Rp. 80.425.000 per year / UT. For Gerga oranges farming activities, the average cost is Rp. 20.665.841,48 per year / UT. And it found that of the 4 independent variables tested, the land area has a significant effect on revenue with $t$ table $>t$ count, amounting to 2,394. Meanwhile, if the F test carried out together, then the fcount <ftabel was obtained, then Ho was accepted and Ha was rejected. Means together with independent veriabel there was no significant effect on the dependent variable in the revenue case.

Keywords; Gerga oranges, farmer business, Rimbo Pengadang
\end{abstract}

\section{PENDAHULUAN}

Wilayah Provinsi Bengkulu khususnya Kabupaten Lebong merupakan salah satu daerah yang memiliki aneka potensi yang menunjang perekonomian nasional, baik itu potensi pertanian, perkebunan, perikanan, peternakan maupun kehutanan. Pada bidang pertanian, wilayah Kabupaten ini merupakan daerah yang cocok untuk pengembangan berbagai jenis tanaman hortikultura seperti jeruk gerga, karena daerah ini didukung oleh keadaan kondisi tanah yang gembur dan subur dan 


\section{DOI: $\underline{\text { https://doi.org/10.32663 }}$}

letak wilayah dengan ketinggian wilayah yang berkisar antara $800-1.000 \mathrm{mdpl}$.

Salah satu jenis jeruk yang dikembangkan di Provinsi Bengkulu adalah jeruk Gerga Lebong (RGL). Jeruk ini merupakan komoditas unggulan Kabupaten Lebong karena mempunyai keunggulan kompetitif, yaitu buahnya berwarna kuningorange, berbuah sepanjang tahun, ukuran buah besar 200-350 gram dan kadar sari buah tinggi (Suwantoro, 2009). Salah satu daerah penghasil komoditi jeruk gerga di Kabupaten Lebong adalah Desa Rimbo Pengadang Kecamatan Rimbo Pengadang. Sebagian besar masyarakat di Desa ini mengusahakan jeruk gerga sebagai sumber mata pencaharian mereka.

Tujuan penelitian ini untuk mengetahui pendapatan usahatani jeruk gerga di Desa Rimbo Pengadang, pengaruh antara luas lahan, umur, pendidikan, dan jumlah tanggungan keluarga terhadap pendapatan usahatani jeruk gerga di Desa Rimbo Pengadang dan untuk Mengetahui perkembangan usaha tani Jeruk Gerga di Desa Rimbo Pengadang dalam 5 Tahun Terakhir.

\section{BAHAN DAN METODE}

Penelitian ini dilaksanakan di Desa Rimbo Pengadang Kecamatan Rimbo Pengadang Kabupaten Lebong, Penentuan lokasi penelitian ditentukan dengan metode purposive atau ditentukan dengan sengaja. Dengan pertimbangan bahwa Desa Rimbo Pengadang adalah Desa yang masyarakatnya bekerja sebagai petani holtikultura salah satunya yaitu usahatani jeruk gerga. Responden pada penelitian ini di tentukan secara acak sederhana (Simpel Random Sampling) sebanyak $30 \%$ dari jumlah populasi yang ada (petani jeruk gerga) di Desa Rimbo Pengadang. Data yang digunakan dalam penelitian ini berupa data primer dan sekunder. Metode analisis data yang digunakan untuk mengetahui biaya penerimaan dan pendapatan usaha tani jeruk gerga adalah :Biaya usaha tani; $\mathrm{TC}=\mathrm{FC}+\mathrm{VC}$. Untuk menghitung penerimaan usaha tani dilakukan dengan cara jumlah produksi per hektar dikali dengan harga jual per satuan $\mathrm{kg}$ dengan rumus: $\mathrm{TR}=\mathrm{P} \mathrm{X}$ Q. Metode yang digunakan untuk mengetahui efisiensi usaha tani jeruk gerga digunakan rumus :

$$
\mathrm{R} / \mathrm{C} \text { Ratio }=\frac{\text { Penerimaan }}{\text { Biaya }}
$$

Untuk menguji faktor-faktor yang mempengaruhi pendapatan usahatani digunakan analisis linier berganda, dengan rumus sebagai berikut :

$\mathrm{Y}=a+b_{1} X_{1}+b_{2} X_{2}+b_{3} X_{3}+b_{4} X_{4}$

Dimana :

$$
\begin{array}{ll}
\mathrm{Y} & =\text { pendapatan }(\mathrm{Rp}) \\
X_{1} & =\text { Luas Lahan }(\mathrm{Ha}) \\
X_{2} & =\text { Umur petani (thn) } \\
X_{3} & =\text { pendidikan petani (Thn) } \\
X_{4} & =\quad \text { jumlah tanggungan } \\
\text { keluarga (jiwa) } & \\
b_{1} b_{2} b_{3} b_{4} & =\text { koefisien regresi } \\
a & =\text { intercept }
\end{array}
$$

Uji F dapat dihitung sebagai berikut ;

$$
\text { Fhitung }=\frac{\mathrm{R}^{2} / \mathrm{K}-1}{\left(1-\mathrm{R}^{2}\right) / \mathrm{N}-\mathrm{K}}
$$

Dimana :

$\mathrm{R}^{2}=$ Koefisien Determinasi

$\mathrm{K}=$ Jumlah Variabel

$\mathrm{N}=$ Jumlah Populasi

1. Jika Fhit $\leq$ Ftabel, maka Ho diterima Ha di tolak, berarti secara bersamasama variabel bebas tidak 
berpengaruh nyata terhadap variabel terikat

2. Jika F hit > F tabel, maka Ho ditolak Ha diterima, berarti secara bersamasama variabel bebas berpengaruh nyata terhadap variabel terikat. Sedangkan untuk menghitung masing-masing variabel digunakan uji t, Adapun secara sistematis dituliskan sebagai berikut;

$\mathrm{t}$ hit $=\underline{\beta i}$ $S \beta i$

Dimana ;

$\beta \mathrm{i}=$ koefisien regresi variable

$\mathrm{i} \quad=1,2,3,4 \ldots$

$\mathrm{S} \beta \mathrm{i}=$ Standar eror dari masing - masing Variabel

Hipotesa yang diujikan adalah sebagai berikut ;

Ho ; $\beta \mathrm{i}=0$

$\mathrm{Ha} ; \beta \mathrm{i} \neq 0$
Dengan kriteria pengambilan keputusan sebagai berikut :

1. Jika $\mathrm{t}$ hit $\leq \mathrm{t}$ tabel, maka Ho diterima Ha ditolak berarti secara individu variabel bebas tidak berpengaruh nyata terhadap variabel terikat

2. Jika $t$ hit $>\mathrm{t}$ tabel, maka Ho di tolak Ha diterima, berarti secara individu variabel bebas berpengaruh nyata terhadap variabel terikat.

\section{HASIL DAN PEMBAHASAN}

Dari tabel 1 ini kita ketahui bahwa rata rata umur petani jeruk Gerga 45,718 dengan kisaran 27-63. Hal ini memperlihatkan bahwa rata rata petani jeruk gerga ada pada usia produktif di mana pada usia produktif ini biasanya usaha termaksimal di lakukan oleh seseorang untuk mendapatkan pendapatan.

Tabel 1. Karakteristik petani jeruk Gerga di Desa Rimbo Pengadang Kecamatan Rimbo Pengadang Kabupaten Lebong

\begin{tabular}{|c|c|c|c|c|}
\hline No & Karakteristisk & Persentase & Rata Rata & Kisaran \\
\hline 1 & Umur & & 45,718 & $27-63$ \\
\hline 2 & Luas lahan & & 1,86 & $0,5-5$ \\
\hline \multirow[t]{5}{*}{3} & \multicolumn{4}{|l|}{ Pendidikan } \\
\hline & Tamatan SD/Sederajat & \multicolumn{3}{|l|}{$37,5 \%$} \\
\hline & Tamatan SLTP/Sederajat & \multicolumn{3}{|l|}{$12,5 \%$} \\
\hline & Tamatan SLTA/Sederajat & \multicolumn{3}{|l|}{$34,38 \%$} \\
\hline & Diploma/Sarjana & \multicolumn{3}{|l|}{$15,63 \%$} \\
\hline 4 & $\begin{array}{l}\text { Jumlah } \\
\text { Keluarga }\end{array}$ & Tanggungan & 2,56 & $1-5$ \\
\hline \multirow[t]{3}{*}{5} & Pekerjaan & & & \\
\hline & Petani & \multicolumn{3}{|l|}{96,87} \\
\hline & PNS & \multicolumn{3}{|l|}{3,13} \\
\hline
\end{tabular}

Sumber : Data Primer di olah, 2018 


\section{DOI: $\underline{\text { https://doi.org/10.32663 }}$}

Sementara itu luas lahan yang dimiliki oleh Petani Jeruk Gerga rata rata 1,86 Ha. Dan semuanya milik pribadi. Hal ini disebabkan petani jeruk Gerga di Desa Rimbo Pengadang penduduk yang nenek moyangnya memang tinggal di sana dan secara turun temurun melakukan aktifitas kegiatan usaha tani, yang salama ini usaha tani kopi.

Tingkat pendidikan petani Jeruk gerga persentase tertinggi adalah tamat SD/Sederajat sebesar 37,5\%. Di ikuti oleh Tamat SLTA/Sederajat sebesar 34,38\%, tamat Diploma 15,63\% dan tamat SLPT sebesar $12,5 \%$. Dari data ini terlihat bahwa tingkat pendidikan petani Jeruk Gerga tertinggi tamat SD/Sederajat diikuti dengan Tamat SLTA/Sederajar, berarti hampir sebagian besar petani jeruk gerga tingkat pendidikannya merata dalam kategori rendah dan sedang. Tingkat Pendidikan yang rendah ini dapat mempengaruhi pengetahuan petani dalam melakukan kegiatan usaha tani tetapi bisa saja tidak mempengaruhi jika petani nya mau belajar mandiri karena saat ini ada pendidikan non formal berupa kegiatan penyuluhan pertanian dan juga dukungan informasi yang dengan mudah di peroleh oleh petani pada zaman sekarang, baik itu melalui penyuluh pertanian, distributor penyedia saprodi dan kemudahan untuk memperoleh akses informasi melalui media sosial.

Jumlah Tanggungan keluarga petani jeruk gerga rata rata 2,56 berkisar antara 1-5 orang. Jumlah Tanggung keluarga yang tidak terlalu besar ini memberikan kesempatan kepada petani untuk bisa mengalokasikan penghasilan mereka untuk mensuport kebutuhan usaha tani jeruk gerga seperti pemupukan, penyemprotan dan kegiatan lainnya yang mendukung kegiatan usaha tani jeruk Gerga.

Tabel 2. Rata rata biaya usaha tani jeruk Gerga di Desa Rimbo Pengadang Kecamatan Rimbo Pengadang Kabupaten Lebong tahun 2018

\begin{tabular}{lc}
\hline \multicolumn{1}{c}{ Uraian } & $\begin{array}{c}\text { Rata -Rata Biaya Usahatani Jeruk Gerga } \\
(\mathrm{Rp} / \mathrm{Ut})\end{array}$ \\
\hline a Biaya Tetap (FC) & $37.187,5$ \\
1. Pajak & $565.407,89$ \\
2. Biaya penyusutan alat & $602.595,39$ \\
Rata-Rata Biaya Tetap & \\
b.Biaya Tidak Tetap & $7.074 .218,75$ \\
1. Bibit & $6.688 .457,03$ \\
2. Pupuk & $787.289,06$ \\
3. Pestisida & $5.182 .812,50$ \\
4. Tenaga Kerja & $330.468,75$ \\
5. Biaya Transportasi & $20.063 .246,09$ \\
Rata-rata biaya variabel & $20.665 .841,48$ \\
\hline Total biaya usahatani &
\end{tabular}

Sumber : Data primer setelah diolah 2018. 
Tabel 3. Rata-rata penerimaan dan pendapatan usahatani jeruk Gerga di Desa Rimbo Pengadang tahun 2018

\begin{tabular}{|c|c|c|c|}
\hline \multirow{2}{*}{ No } & \multirow{2}{*}{ Uraian } & \multicolumn{2}{|c|}{ Rata-rata } \\
\hline & & Fisik (Kg/th) & Rupiah/Ut/tahun \\
\hline & Produksi & $5.771,876$ & - \\
\hline 2. & Penerimaan & - & 80.425 .000 \\
\hline 3. & Biaya Usahatani & - & $20.665 .841,48$ \\
\hline 4. & Pendapatan Usahatani & - & $59.759 .158,52$ \\
\hline
\end{tabular}

Sumber : Data Primer Setelah diolah 2018

Dari hasil penelitian juga di ketahui bahwa 96,87\% kegiatan usaha tani Jeruk Gerga ini merupakan pekerjaan utama responden dan menjadi sumber utama dalam memenuhi kebutuhan kebutuhan keluarga sehingga mereka secara sungguh sungguh melakukan kegiatan Usaha Tani Jeru Gerga agar bisa berhasill dan menghasilkan pendapatan untuk keluarga mereka.

Dari tabel 3 kita ketahui jumlah produksi jeruk gerga yang di hasilkan petani sebanyak 5.771,867 kg/tahun. Rata rata penerimaan yang di peroleh oleh petani sebesar Rp. 80.425.000 pertahun dengan rata rata total biaya produksi sebesar $\mathrm{Rp}$. 20.665.841,48. Dan dari hasil perhitungan pendapatan yang diperoleh sebesar Rp, 59.759.158,52 pertahun. Artinya usahatani jeruk gerga menguntungkan bagi petani karena besarnya penerimaan bisa menutupi seluruh biaya yang di keluarkan dalam kegiatan usaha tani Jeruk Gerga. Dan pada saat di lakukan penelitian kondisi yang di temui ternyata petani yang mengusahakan usahatani Jeruk Gerga ini awalnya merupakan petani kopi yang beralih ke kegiatan usahatani Jeruk Gerga.

Dari analisa yang di lakukan, di dapatkan bahwa nilai $\mathrm{R} / \mathrm{C}$ ratio sebesar 3,89. Nilai ini $>1$ menunjukkan bahwa usaha tani jeruk gerga efisien dan menguntungkan untuk di lakukan. Nilai
$\mathrm{R} / \mathrm{C}$ ratio yang $>1$ ini bisa jadi merupakan penyebab banyak petani di Desa Rimbo Pengadang ini yang awalnya melakukan kegiatan usahatani kopi beralih ke usahatani Jeruk Gerga.

\section{Pengujian Secara Simultan (Uji-F)}

Secara simultan, pengaruh antara luas lahan, umur, tingkat pendidikan dan jumlah tanggungan keluarga dapat diketahui dengan uji-F. Berdasarkan hasil regresi diperoleh hasil $\mathrm{F}_{\text {hitung }}$ sebesar 1,592 dan nilai $F_{\text {tabel }}$ sebesar 2,278 sehingga dapat diketahui bahwa nilai $\mathrm{F}_{\text {hitung }}(1,592)$ $<\mathrm{F}_{\text {tabel }}(2,278)$. Ini berarti bahwa luas lahan, umur, tingkat pendidikan dan jumlah tanggungan keluarga secara bersamaan tidak berpengaruh nyata terhadap pendapatan usahatani jeruk gerga pada kegiatan usahatani jeruk gerga di daerah penelitian.

Berdasarkan uraian diatas dapat diambil kesimpulan bahwa hipotesis yang menyatakan adanya pengaruh luas lahan, umur, tingkat pendidikan dan jumlah tanggungan keluarga secara bersamaan terhadap pendapatan usahatani jeruk gerga tidak dapat diterima $\left(\mathrm{H}_{0}\right.$ diterima dan $\mathrm{Ha}$ ditolak). 


\section{DOI: $\underline{\text { https://doi.org/10.32663 }}$}

Tabel 4. Analisis Faktor-Faktor Yang Mempengaruhi Pendapatan Petani Jeruk Gerga di Daerah Penelitian.

\begin{tabular}{llccrrrr}
\hline No. & \multicolumn{1}{c}{ Variabel } & Koefisien Regresi & $\begin{array}{c}\text { Standart } \\
\text { Error }\end{array}$ & $\mathbf{T}_{\text {hitung }}$ & $\mathbf{T}_{\text {tabel }}$ & Signifikan & Ket \\
\hline 1. & lahan $\left(\mathrm{X}_{1}\right)$ & 0,431 & 0,122 & 2,394 & 2,052 & 0,024 & $*$ \\
2. & Umur $\left(\mathrm{X}_{2}\right)$ & 0,054 & 0,298 & 0,241 & 2,052 & 0,812 & $\mathrm{TN}$ \\
3. & Pendidikan $\left(\mathrm{X}_{\mathrm{a}}\right)$ & 0,043 & 0,204 & 0,193 & 2,052 & 0,848 & $\mathrm{TN}$ \\
& Jml.Tanggungan & 0,015 & 0,266 & 0,084 & 2,052 & 0,933 & $\mathrm{TN}$ \\
4. & Keluarga $\left(\mathrm{X}_{4}\right)$ & & & & & &
\end{tabular}

Konstanta $:-8,166 \mathrm{E} 7$

$R^{2} \quad: 0,071$

F hitung $: 1,592$

Ftabel $: 2,278$

Keterangan : $*$ Nyata pada taraf kepercayaan $95 \%$

$\mathrm{TN}=$ Tidak Nyata

Sumber : Data Primer Setelah diolah 2018

Berdasarkan tabel 4, diperoleh fungsi pendapatan pada usahatani jeruk gerga yang dapat dirumuskan sebagai berikut :

$$
\begin{gathered}
\mathrm{Y}=-8,166 \mathrm{E} 7+0,431 \mathrm{X}_{1}+0,054 \mathrm{X}_{2}+ \\
0,043 \mathrm{X}_{3}+0,015 \mathrm{X}_{4}+\mathrm{e}
\end{gathered}
$$

\section{Pengujian Secara Parsial (Uji-T)}

Secara parsial, pengaruh antara luas lahan, umur, tingkat pendidikan dan jumlah tanggungan keluarga terhadap pendapatan petani jeruk gerga dapat diketahui dengan menggunakan uji t. Berdasarkan tabel 4 dapat diketahui bahwa :

1. Variabel bebas luas lahan $\left(\mathrm{X}_{1}\right)$ mempunyai nilai $t$ hitung sebesar 2,394 dan nilai $\mathrm{t}$ tabel sebesar 2,052. Ini menunjukkan nilai $\mathrm{t}$ hitung lebih besar dari nilai $\mathrm{t}_{\text {tabel }}$ yang berarti $\mathrm{H}_{0}$ ditolak dan Ha diterima. Jadi dapat di diketahui bahwa luas lahan mempunyai pengaruh yang nyata terhadap pendapatan petani karena ketika luas lahan bertambah maka pendapatan petani akan meningkat. Hal ini berarti bahwa besar kecilnya luas lahan yang dimiliki petani berpengaruh nyata terhadap tingkat pendapatan petani. Hal ini sesuai dengan pendapat Hermanto dalam Chuzaimah et all (2016) yang menyatakan bahwa semakin luas lahan usahatani yang digarap, ternyata mampu menghasilkan produksi yang lebih banyak sehingga penerimaan dan pendapatan juga meningkat. Koefisien regresi sebesar 0,431 menunjukkan bahwa setiap penambahan luas lahan sebesar 1 Ha akan meningkatkan pendapatan petani sebesar 0,431 dengan asumsi variabel independen yang lainnya konstan.

2. Variabel bebas umur $\left(\mathrm{X}_{2}\right)$ mempunyai nilai $t_{\text {hitung }}$ sebesar 0,241 dan nilai $t_{\text {tabel }}$ sebesar 2,052. Ini menunjukkan nilai $t_{\text {hitung }}$ lebih kecil dari nilai $t_{\text {tabel }}$ yang berarti $\mathrm{H}_{0}$ diterima dan Ha ditolak. Jadi dapat dijelaskan bahwa tingkat umur petani tidak berpengaruh nyata terhadap pendapatan. Rata-rata umur petani responden di daerah penelitian sebesar 45,718 tahun yang tergolong dalam kelompok usia produktif. Menurut Heryana 


\section{DOI: $\underline{\text { https://doi.org/10.32663 }}$}

mengemukakan bahwa penduduk yang tergolong dalam kelompok usia produktif adalah penduduk yang masuk kedalam kategori umur 15 sampai 64 tahun. Jadi hal ini membuat petani masih mampu untuk terus berusahatani secara produktif untuk meningkatkan hasil produksi. Koefisien regresi sebesar 0,054 menunjukkan bahwa setiap peningkatan umur 1 tahun berpengaruh nyata terhadap pendapatan petani sebesar 0,054 dengan asumsi variabel independen yang lainnya konstan.

3. Variabel bebas tingkat pendidikan $\left(\mathrm{X}_{3}\right)$ mempunyai nilai $t_{\text {hitung }}=0,193$ yang lebih kecil dari nilai $t_{\text {tabel }}=2,052$. Ini menunjukkan nilai $t_{\text {hitung }}$ lebih kecil dari nilai $\mathrm{t}_{\text {tabel }}$ yang berarti $\mathrm{H}_{0}$ diterima dan Ha ditolak. Hal ini berarti bahwa tingkat pendidikan tidak berpengaruh nyata terhadap pendapatan petani karena bila dirata-ratakan tingkat pendidikan petani di daerah penelitian hanya 9,9 tahun dan itu hanya setara Sekolah Menengah Pertama dan masih tergolong rendah, sehingga dalam mengelola kegiatan usahataninya petani masih berdasarkan pengalaman yang turun temurun dan belum mampu menguasai dan menyesuaikan diri dengan teknologi modern dan tepat guna, disamping itu di dalam dunia pendidikan hanya mempelajari berbagai ilmu pengetahuan umum saja dan tidak menjurus pada dunia pertanian sehingga petani belum begitu mengetahui tentang dunia pertanian khususnya mengenai budidaya tanaman jeruk gerga. Sesuai dengan pendapat Shoimus Sholeh, et all (2013) yang menyatakan bahwa tingkat pendidikan tidak berpengaruh nyata terhadap efek inefisiensi teknis dalam berusahatani jeruk gerga karena didalam pendidikan formal hanya belajar tentang pengetahuan umum dan bukan memberikan informasi tentang pertanian, sehingga tingginya tingkat pendidikan tidak menentukan semakin rendahnya tingkat inefisiensi. Koefisien regresi sebesar 0,193 berarti jika tingkat pendidikan bertambah tinggi sebesar 1 tahun maka tidak akan mempengaruhi pendapatan petani sebesar sebesar 0,193 dengan asumsi variabel independen yang lainnya dianggap konstan.

4. Variabel bebas jumlah tanggungan keluarga $\left(\mathrm{X}_{4}\right)$ mempunyai nilai $\mathrm{t}_{\text {hitung }}=$ 0,084 yang lebih kecil dari nilai $t_{\text {tabel }}=$ 2,052 yang berarti $\mathrm{H}_{0}$ diterima dan $\mathrm{Ha}$ ditolak. Hal ini berarti bahwa jumlah tanggungan keluarga tidak berpengaruh nyata terhadap pendapatan petani karena semakin banyak anggota keluarga dalam rumah tangga petani maka kebutuhan keluarga juga semakin tinggi. Sesuai dengan pendapat Hernanto dalam Fikriman dan Herdiansyah, A (2015), bahwa seseorang yang mempunyai jumlah tanggungan yang lebih besar akan diburu oleh kebutuhan keluarga, dengan demikian ia akan berusaha semaksimal mungkin untuk memenuhi kebutuhannya. Koefisien regresi sebesar 0,015 artinya jika jumlah tanggungan keluarga bertambah 1 jiwa tidak berpengaruh nyata terhadap pendapatan sebesar 0,015 dengan asumsi variabel independen yang lainnya konstan.

\section{Koefisien Determinasi $\left(\mathrm{R}^{2}\right)$}




\section{DOI: $\underline{\text { https://doi.org/10.32663 }}$}

Nilai koefisien determinasi $\left(\mathrm{R}^{2}\right)$ sebesar 0,071 dapat dijelaskan bahwa pendapatan usahatani jeruk gerga di daerah penelitian sebesar $0,71 \%$ dipengaruhi oleh luas lahan, umur, tingkat pendidikan dan jumlah tanggungan keluarga. Dan selebihnya sebesar 99,29\% dipengaruhi oleh faktor-faktor yang tidak diteliti dalam penelitian ini. Dengan demikian, hipotesis yang menyatakan bahwa umur $\left(\mathrm{X}_{2}\right)$, tingkat pendidikan (X3) dan jumlah tanggungan keluarga $\left(\mathrm{X}_{4}\right)$ secara parsial berpengaruh nyata terhadap pendapatan (Y) tidak dapat diterima $\left(\mathrm{H}_{0}\right.$ diterima dan $\mathrm{Ha}$ ditolak), sedangkan variabel Luas Lahan $\left(\mathrm{X}_{1}\right)$ secara parsial berpengaruh nyata terhadap pendapatan sehingga hipotesis dapat diterima $\left(\mathrm{H}_{0}\right.$ ditolak dan $\mathrm{Ha}$ diterima).

\section{KESIMPULAN}

Besarnya pendapatan yang di peroleh dari usaha tani jeruk gerga senilai Rp 59.759.158,52 /UT pertahun. Nilai R/C Ratio kegiatan usahatani Jeruk Gerga senilai 3,89. Nilai ini $>1$ menunjukkan bahwa usaha tani jeruk gerga efisien dan menguntungkan untuk di lakukan. Nilai $\mathrm{R} / \mathrm{C}$ ratio yang $>1$ ini bisa jadi merupakan penyebab banyak petani di Desa Rimbo Pendagang yang awalnya melakukan kegiatan usahatani kopi beralih ke usahatani Jeruk Gerga. Luas lahan berpengaruh nyata terhadap pendapatan petani jeruk gerga, sementara umur, pendidikan dan tanggungan keluarga tidak berpengaruh nyata terhadap pendapatan petani jeruk Gerga. Dalam 5 tahun terakhir perkembangan Jeruk Gerga makin pesat ini di tandai dengan makin banyak nya petani yang melakukan usahat tani jeruk gerga dan beralih dari usaha tani kopi ke usaha tani Jeruk Gerga

\section{UCAPAN TERIMA KASIH}

Ucapan terimakasih disampaikan kepada Direktorat Riset dan Pengabdian Masyarakat Direktorat Jenderal Penguatan Riset dan Pengembangan Kementerian Riset, Teknologi, dan Pendidikan Tinggi sesuai dengan Kontrak Penelitian Tahun Anggaran 2018.

\section{DAFTAR PUSTAKA}

BP3. 20117. Rimbo pengadang dalam angka 2017. BP3 kabupaten lebong.

Naiggolan, 2013. Analisis Usaha Tani Jeruk dan Faktor Faktor yang mempengaruhi Penerimaan petani di Kabupaten Dairi, (Studi Kasus :Desa Perjuangan, Kecamatan Sumbul Kabupaten Dairi). Skripsi Program Studi Agribisnis, Fakultas Pertanian, Universitas Medan

Prandoa, 2013. Kelayakan dan Analisis Usaha Tani Jeruk Siam, Desa Kubu Simbelang Kabupaten Karo.

Rahim \& Hastuti, DRD, 2007, Ekonomika Pertanian (Pengantar, Teori danKasus), Penebar Swadaya, Jakarta.

Rahim dan Hastuti, 2008. Pengantar, Teori dan Kasus Ekonomika Pertanian. Jakarta Penebar Swadaya

Rahmanta, 2016, qejournal.unimed.ac.id/journal/index.php/ QEJ/article/.../88/56, di unggah pada tanggal 4 desember 2016

Sastradiharja, S. 2006. Menanam Sayuran Secara Organik. Jakarta. Azka Press

Silalahi, 2010. Metode Penelitian Sosial. Jakarta 


\section{DOI: $\underline{\text { https://doi.org/10.32663 }}$}

Sugeng, HR. 1981. Bercocok Tanam

Sayuran. Semarang. PT. Pabelan

Cerdas Nusantara

Suryani, M, Rambae, 2012. Pengkajian

Teknologi pembungaan dan

Pembuahan Jeruk Gerga di Lebong, 2012

Suwantoro, B., 2010. Mengenal jeruk rimau gerga lebong lebih dekat. Balai benih hortikultura Rimbo Pengadang. Dinas Pertanian dan Ketahanan Pangan Kabupaten Lebong

Saputra, R. 2016, Evaluasi kesesuaian lahan untuk pengembangan jeruk gerga (citrus sp.) Di kecamatan rimbo pengadang Dan topos kabupaten lebong. Skripsi Program Studi Agroekoteknologi Jurusan Budiday Pertanian Fakultas Pertanian Universitas Bengkulu. http://repository.unib.ac.id/14530/. Di unggah pada tanggal 13 November 2017

Wanda, Faisal. 2015. Analisis Pendapatan Usaha Tani Jeruk Siam (Studi Kasus Di Desa Padang Pangrapat Kecamatan Tanah Grogot Kabupaten Paser). eJournal Ilmu Administrasi Bisnis, 2015, 3 (3): 600-611 ISSN 2355-5408, ejournal.adbisnis.fisipunmul.ac.id (C) Copyright 2015. Di unduh pada tanggal 26 Juni 2018 